IP Periodica Polytechnica Civil Engineering

\author{
62(2), pp. 470-479, 2018 \\ https://doi.org/10.3311/PPci.8139 \\ Creative Commons Attribution (i)
}

RESEARCH ARTICLE

\section{Use of the Artificial Neural Networks to Estimate the DRF for Eurocode 8}

\author{
Baizid Benahmed $^{1 *}$, Malek Hamoutenne ${ }^{2}$
}

Received 06 April 2015; Revised 07 February 2017; Accepted 03 January 2018

\begin{abstract}
The damping reduction factor (DRF) is used in earthquake engineering in order to estimate the seismic response of buildings with high damping ratio from the one which has damping ratio equal to 5\%. Many expressions were given to this factor as a function of different parameters in literature. The concern of these formulations is to find a simple and a reliable formulation, which presents a challenge. This is the major reason to look for a new simple method to estimate the DRF values with a good approximation. The primary objective of this work is to develop a new method to estimate the DRF using Artificial Neural Networks (ANN). This method is developed for the seismic Eurocode 8 (EC8). In a first step, seeking for sets of ground motions records that gives as average the best approximation of the target spectra of EC 8. Afterward, those records are used to estimates the exact response spectra and the DRF values in function of damping ratio $\xi$ and period (T) through a time History Analysis. In a second step, those results are used as neural networks database to predict the DRF in function of $\xi$ and T. The proposed approach is original and the associated results are interesting and promising.
\end{abstract}

\section{Keywords}

ground motions, Damping Reduction Factor (DRF), Artificial Neural Networks (ANN), Eurocode 8

1 Civil Engineering Department, University of Djelfa, 17000 Djelfa, Algeria

2 Department of Civil Engineering, Polytechnic National School (ENP), Avenue des Frères Ouddak, Hacen Badi,B.P.182, EL-HARRACH, 16200, Algiers, Algeria.

* Corresponding author, email: benahmed.tp@gmail.com

\section{Introduction}

In the most seismic codes throughout the world, the response spectrum is given for a damping ratio $\xi=5 \%$. Civil structures, however, may have different values of damping. As a result, the $5 \%$ response spectrum should be adjusted to other damping levels through a correction factor to evaluate the spectral response for any damping 1 .

Different symbols are cited in the literature to identify this correction factor. For instance, DCF "Damping Correction Factor" is used in [1-4], "Damping reduction factor" is used by [5-9], and several other researchers. "Damping modification factor" is used in [10-13]. Other terminologies that have seen in the literature include: damping adjustment factor, response spectrum amplification factor, and the damping scaling factor. In this study, we adopt the term Damping Reduction Factor (DRF).

This factor has been studied by a number of researchers. Moreover, many expressions were given to this factor as a function of many parameters, damping only [3, 4, 14-16], Damping and period $[6,17-21]$, or other parameters Duration, Soil conditions, Distance, Magnitude).

One of the first systematic methods, for adjusting 5\%-damped spectra to other levels of damping, was the pioneer work of Newmark and Hall [22] where their results inspired many seismic codes and Norms. It was based on only 28 records from 9 earthquakes prior to 1973. This work is the basis for most U.S. building codes. They divided their results of damping reduction factors into three parts: the acceleration-, velocity-, and displacement-sensitive regions, respectively. The model of Newmark and Hall is only applicable for $\xi<20 \%$ and for $T$ in the range 0.125-10 sec. In Lin and Chang [6], a total of 1053 earthquake acceleration time histories from 102 earthquakes recorded in the United States of America. They concluded that the damping reduction factors are functions of the structural period and the damping ratio. Its applicability is $\xi-2-50 \%$ and $T 0.01-10 \mathrm{sec}$.

Hatzigeorgiou [12] in his paper proposed a new method to estimate DRF of SDOF systems on the basis of empirical expressions obtained after extensive parametric studies. The influence of viscous damping ratio, period of vibration, soil type conditions and ground motion type (natural near- and 
far-fault and artificial accelerograms) are carefully examined and discussed. A complete nonlinear regression analysis is carried out on the basis of the data obtained by the aforementioned response analysis. The relation of DRF versus the structural period and viscous damping ratio is regressed in such a way so that the effect of soil type and the type of seismic ground motion should be also taken into account.

Stafford et al [2] in their paper confirmed the dependence of damping reduction factors for response spectra on duration and numbers of cycles inferred by Bommer and Mendis [23] They quantified this dependence through the development of equation for predicting spectral scaling factors as functions of these parameters. Its applicability is in the interval of $\xi 2-55 \%$. Cameron and Green [1] proposed an equation for the damping reduction factors for $\xi \geq 2 \%$ vary as a function of general site classification, earthquake magnitude, and tectonic setting. Its Applicability is limited in $T=0.05-10 \mathrm{sec} \xi=1-50 \%$, Magnitude bins: 5-6, 6-7, 7+, Distance bins: 0-50, 50-200 km.

Lin et al [5] have made a comparison and an evaluation of existing models against a database of recorded motions. They evaluated the accuracy of five types of damping reduction factors for estimating the maximum elastic displacement demands of SDOF systems by using 216 ground motions recorded on firm sites in California. In the work of Lin et al [7], a comprehensive statistical study of the damping reduction factors considering the effects of site conditions has been carried out by using 1037 earthquake acceleration time histories recorded on three different site categories (site Class $\mathrm{AB}=$ rock, site Class $\mathrm{C}=$ very dense soil, and site Class $\mathrm{D}=$ stiff soil). Expressions obtained from nonlinear regression analysis by using the Levenberg- Marquardt method which are proposed in the end of their paper in order to estimate the damping reduction factors derived from the displacement and acceleration responses. The resulting equations for the damping reduction factors derived from the displacement response spectrum corresponding to each site class.

Almost of the cited papers used the linear or nonlinear regression to establish a formulation of the damping reduction factor. The disadvantages of those expressions are the exactitude which is not always so good and the complications of those expressions in function of many parameters. This is the main reason to find out a new method to DRF estimation with a good approximation. The objective of this study is to evaluate the accuracy of the neural networks to predict the DRF according to the Eurocode 8 response spectra.

\section{Ground Motion selection using REXEL}

Rexel is a tool that allows the user to select sets of strong ground motion records that are representative of design ground motions. The user specifies the target response spectrum and the desired characteristics of the earthquake ground motions in terms of earthquake magnitude, source-to-site distance and other seismic characteristics. Rexel then selects the records from the internal database of ground motion records that satisfy the user-specified selection criteria and provide good fits to the target response spectrum.

Like many worldwide codes, Eurocode 8 (EC8) allows the use of real ground-motion records for the seismic analysis of structures. The main condition to be satisfied by the selected set is that the average elastic spectrum does not underestimate the code spectrum, with a $10 \%$ tolerance, in a broad range of periods depending on the structure's dynamic properties. The EC8 prescriptions seem to favor the use of spectrum matching records, obtained either by simulation or manipulation of real records [24].

The average spectrum deviation $(\delta)$ gives a quantitative measure of how much the spectrum of a record deviates from the spectrum of the code. The definition of $(\delta)$ is giving by $\operatorname{Eq}(1)$.

$$
\delta=\left\{\sqrt{\frac{1}{N}} \sum_{i=1}^{N}\left(\frac{S a_{0}\left(T_{i}\right)-S a_{s}\left(T_{i}\right)}{S a_{s}\left(T_{i}\right)}\right)^{2}\right\}
$$

Where $S a_{0}(T)$ represents the pseudo-acceleration ordinate of the single reTicord corresponding to the period $T_{i}$ while $S a_{s}\left(T_{i}\right)$ is the value of the spectral ordinate of the code spectrum at the same period, and $N$ is the number of values within the considered range of periods. Selecting a record set with low $(\delta)$ value allows obtaining of an average spectrum, which is tended to be as close as possible to the code spectrum.

Controlling this parameter may allow choosing combinations characterized by records having the individual spectra relatively close to the reference spectrum, and therefore being narrowly distributed around it.

In fact, it was hard to find record sets which are close to the response spectra. In this work, A set of records which are as close as possible to the Eurocode spectra with different site class with design ground acceleration $a_{g}=0.35$. For each site class we selected 25 records according to its average spectrum deviation $(\delta)$.

In Figures 1, 2, 3, the spectrums of the selected records are represented with its mean spectrums and target spectrums. In the most of the compatibility interval, they approximate very well the design spectral shape.

For the types of soils D and E, no results at all were found. This is primarily due to the number limitation of records on these soils in the data-base.

A full list for all records found for each soil class with their characteristics was presented in the Tables 1, 2, 3 .

\section{Artificial Neural Network Analysis 3.1 Network design}

In order to obtain more realistic prediction of the damping reduction factor, a contemporary data analysis technique, which is capable of searching nonlinear relationships more thoroughly, has been employed. This technique is the neural network analysis. 


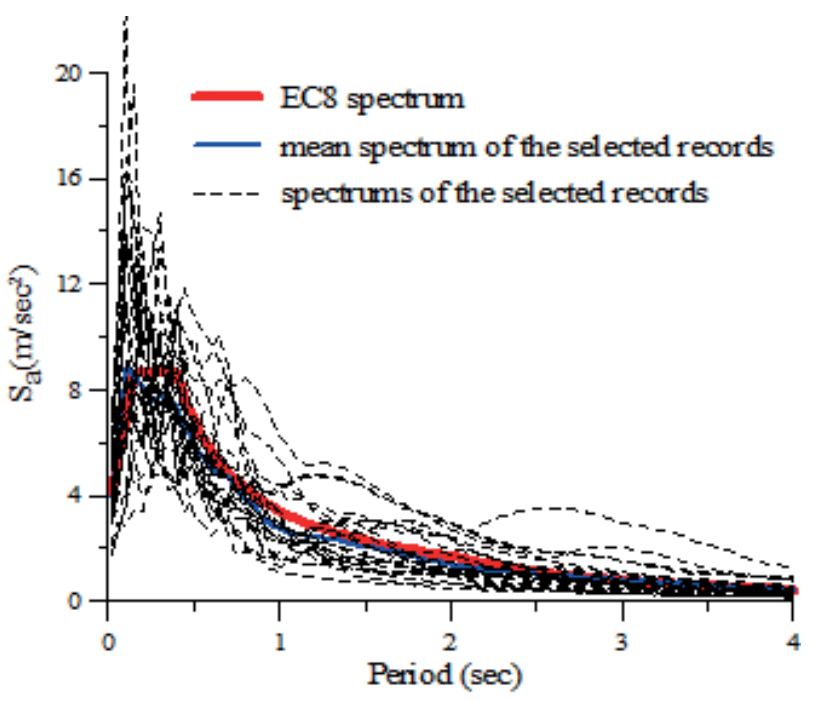

Fig. 1 Response spectrums of the records returned by REXEL for the soil A

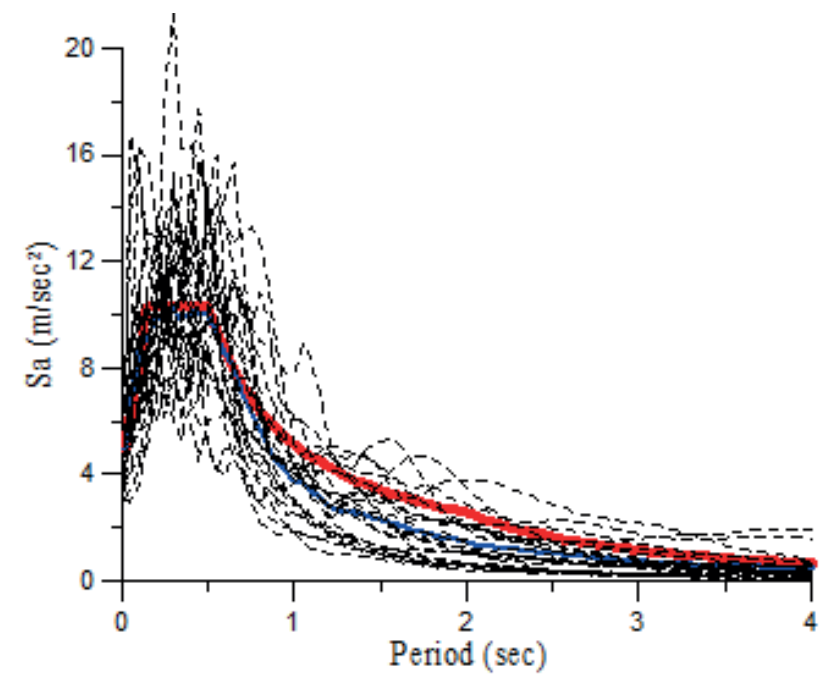

Fig. 2 Response spectrums of the records returned by REXEL for the soil B

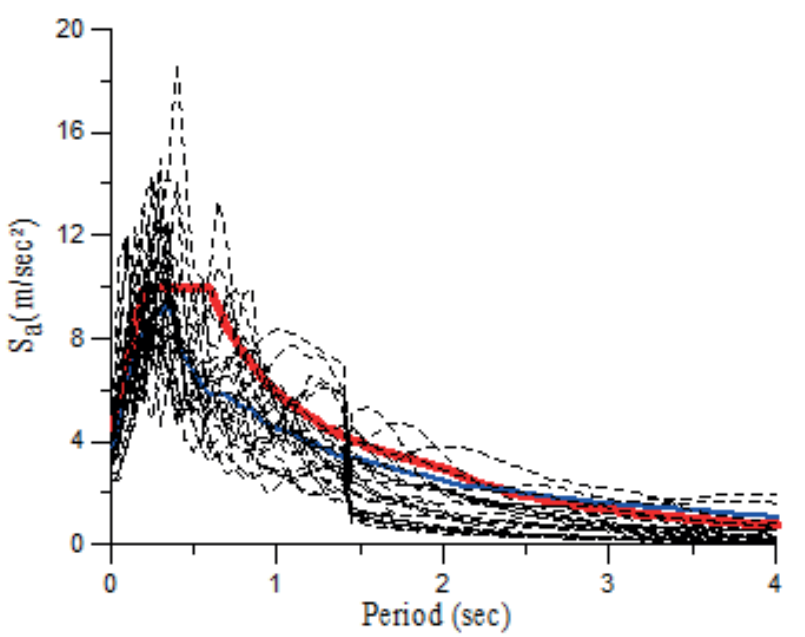

Fig. 3 Response spectrums of the records returned by REXEL for the soil C

Neural network constitutes a branch of artificial intelligence which has recently undergone rapid evolution and progress. Its development started in the 1940s to help cognitive scientists understand the complexity of the nervous system [25]. An Artificial Neural Network (ANN) is an information processing paradigm that is inspired by the learning process in the human brain, the key element of this paradigm is the structure of the information processing system. This computational technique has the ability to learn in a similar way to people. It is capable of recognizing, capturing and mapping features known as patterns contained in a set of data mainly due to the high interconnections of neurons that process information in parallel. A network that has learned the patterns defining the relationship between the input and output of a certain test or process can later be used to predict new conditions for which the results (output) are not known. In this study, we have used the feed-forward multi-layer neural network.

Table 1 records data returned by REXEL for the soil A

\begin{tabular}{|c|c|c|c|c|c|c|c|}
\hline Earthquake ID & component & Station ID & Earthquake Name & Date & Mw & $\mathrm{Vs} 30(\mathrm{~m} / \mathrm{s})$ & Epicentral Distance $(\mathrm{km})$ \\
\hline 34 & $\mathrm{X}, \mathrm{Y}$ & ST20 & Friuli & $06 / 05 / 1976$ & 6,5 & 1021 & 23 \\
\hline 87 & $\mathrm{X}, \mathrm{Y}$ & ST54 & Tabas & $16 / 09 / 1978$ & 7,3 & 826 & 12 \\
\hline 93 & $\mathrm{X}, \mathrm{Y}$ & ST64 & Montenegro & $15 / 04 / 1979$ & 6,9 & 1083 & 21 \\
\hline 146 & $\mathrm{X}, \mathrm{Y}$ & ST96 & Campano Lucano & $23 / 11 / 1980$ & 6,9 & 1100 & 32 \\
\hline 1635 & $\mathrm{X}$ & ST2486 & South Iceland & $17 / 06 / 2000$ & 6,5 & - & 5 \\
\hline 1635 & $\mathrm{X}, \mathrm{Y}$ & ST2558 & South Iceland & $17 / 06 / 2000$ & 6,5 & - & 15 \\
\hline 2142 & $\mathrm{X}$ & ST2483 & South Iceland (aftershock) & $21 / 06 / 2000$ & 6,4 & - & 6 \\
\hline 2142 & $\mathrm{X}$ & ST2558 & South Iceland (aftershock) & $21 / 06 / 2000$ & 6,4 & - & 5 \\
\hline 497 & $\mathrm{X}$ & ST3136 & Duzce 1 & 12/11/1999 & 7,2 & - & 23 \\
\hline 2309 & $\mathrm{Y}$ & ST539 & Bingol & $01 / 05 / 2003$ & 6,3 & 806 & 14 \\
\hline 41 & $\mathrm{X}, \mathrm{Y}$ & $\mathrm{ST}_{-} 106$ & South Iceland & 2000_June_17 & 6,5 & & 5,25 \\
\hline 101 & $\mathrm{X}, \mathrm{Y}$ & $\mathrm{ST}_{-} 113$ & Olfus & 2008_May_29 & 6,3 & & 8,89 \\
\hline 101 & $\mathrm{X}, \mathrm{Y}$ & $\mathrm{ST}_{-} 112$ & Olfus & 2008_May_29 & 6,3 & & 8,25 \\
\hline 101 & $\mathrm{Y}$ & $\mathrm{ST}_{-} 101$ & Olfus & 2008_May_29 & 6,3 & & 7,97 \\
\hline 147 & $\mathrm{X}, \mathrm{Y}$ & MQZ & Christchurch & 2011_June_05 & 5,1 & & 25,3 \\
\hline 94 & $\mathrm{Y}$ & ST_47379 & Loma Prieta & 1989_Oct_18 & 6,9 & 1428 & 28,57 \\
\hline
\end{tabular}


Table 2 records data returned by REXEL for the soil B

\begin{tabular}{|c|c|c|c|c|c|c|c|}
\hline Earthquake ID & component & Station ID & Earthquake Name & Date & Mw & $\mathrm{Vs} 30(\mathrm{~m} / \mathrm{s})$ & Epicentral Distance (km) \\
\hline 93 & $\mathrm{x}, \mathrm{y}$ & ST62 & Montenegro & & 6,9 & 464 & 25 \\
\hline 250 & $\mathrm{y}$ & ST205 & Erzincan & & 6,6 & 421 & 13 \\
\hline 1635 & $\mathrm{y}$ & ST2482 & South Iceland & $17 / 06 / 2000$ & 6,5 & - & 15 \\
\hline 1635 & $\mathrm{y}$ & ST2554 & South Iceland & $17 / 06 / 2000$ & 6,5 & - & 144 \\
\hline 2142 & $\mathrm{y}$ & ST2484 & South Iceland (aftershock) & & 6,4 & - & 12 \\
\hline 27 & $\mathrm{y}$ & KGS005 & NW Kagoshima Prefecture & 19/05/1997 & 6 & 390 & 15,7 \\
\hline 41 & $\mathrm{y}$ & ST_105 & South Iceland & 2000_June_17 & 6,5 & & 14,56 \\
\hline 50 & $\mathrm{x}$ & ISK003 & Off Noto Peninsula & 2007_Marc_25 & 6,7 & 558 & 27,17 \\
\hline 64 & $\mathrm{x}, \mathrm{y}$ & AQG & L'Aquila mainshock & 2009_Apri_06 & 6,3 & 685 & 4,39 \\
\hline 64 & $\mathrm{x}, \mathrm{y}$ & AQV & L'Aquila mainshock & 2009_Apri_06 & 6,3 & 474 & 4,87 \\
\hline 122 & $\mathrm{y}$ & NIG023 & MID NIIGATA PREF & 2011_Marc_11 & 6,2 & 626 & 5,97 \\
\hline 94 & $\mathrm{x}$ & LGPC & Loma Prieta & 1989_Octo_18 & 6,9 & 477,7 & 18,75 \\
\hline 143 & $\mathrm{x}$ & HVSC & Christchurch & 2011_Febr_22 & 5,5 & - & 4,1 \\
\hline 35 & $\mathrm{x}$ & HEC & Hector Mine & 1999_Octo_16 & 7,1 & 684,9 & 28,61 \\
\hline 72 & $\mathrm{x}$ & TLM1 & Friuli 1st shock & 1976_May_06 & 6,4 & 522 & 21,72 \\
\hline 83 & $\mathrm{x}$ & ST_36408 & Parkfield & 2004_Sept_28 & 6 & 371 & 3,02 \\
\hline 83 & $\mathrm{x}$ & ST_36411 & Parkfield & 2004_Sept_28 & 6 & 438 & 12,49 \\
\hline 86 & $\mathrm{x}, \mathrm{y}$ & KAR & Gazli & 1976_May_17 & 6,7 & 659,6 & 12,78 \\
\hline 94 & $\mathrm{x}$ & ST_57007 & Loma Prieta & 1989_Octo_18 & 6,9 & 462 & 7,1 \\
\hline 94 & $\mathrm{y}$ & ST_47006 & Loma Prieta & 1989_Octo_18 & 6,9 & 730 & 28,83 \\
\hline 94 & $\mathrm{y}$ & ST_58065 & Loma Prieta & 1989_Octo_18 & 6,9 & 371 & 27,59 \\
\hline
\end{tabular}

Table 3 records data returned by REXEL for the soil C

\begin{tabular}{|c|c|c|c|c|c|c|c|}
\hline Earthquake ID & component & Station ID & Earthquake Name & Date & $\mathrm{Mw}$ & $\mathrm{Vs} 30(\mathrm{~m} / \mathrm{s})$ & Epicentral Distance $(\mathrm{km})$ \\
\hline 16 & $\mathrm{x}$ & NIG020 & Mid Niigata Prefecture & 2004_October_23 & 6,6 & 354 & 11,09 \\
\hline 54 & $\mathrm{y}$ & SZO016 & S Suruga Bay & 2009_August_10 & 6,2 & 232 & 18,45 \\
\hline 137 & $\mathrm{y}$ & DFHS & Darfield & 2010_Septemb_03 & 7,1 & - & 9,06 \\
\hline 137 & $\mathrm{y}$ & DSLC & Darfield & 2010_Septemb_03 & 7,1 & - & 13,31 \\
\hline 137 & $\mathrm{x}, \mathrm{y}$ & HORC & Darfield & 2010_Septem_03 & 7,1 & - & 17,82 \\
\hline 137 & $\mathrm{y}$ & ROLC & Darfield & 2010_Septemb_03 & 7,1 & - & 16,97 \\
\hline 142 & $\mathrm{y}$ & RHSC & Christchurch & 2011_February_21 & 6,2 & - & 13,73 \\
\hline 77 & $x, y$ & AI_137_DIN & Dinar & 1995_October_01 & 6,4 & 198,1 & 0,47 \\
\hline 89 & $\mathrm{x}$ & AEP & Imperial Valley & 1979_October_15 & 6,5 & 274,5 & 2,31 \\
\hline 89 & $\mathrm{x}, \mathrm{y}$ & $\mathrm{EC} 04$ & Imperial Valley & 1979_October_15 & 6,5 & 208,9 & 27,03 \\
\hline 89 & $\mathrm{x}, \mathrm{y}$ & $\mathrm{EC} 05$ & Imperial Valley & 1979_October_15 & 6,5 & 205,6 & 27,68 \\
\hline 89 & $\mathrm{x}, \mathrm{y}$ & EC06 & Imperial Valley & 1979_October_15 & 6,5 & 203,2 & 27,35 \\
\hline 94 & $\mathrm{x}$ & ST_47125 & Loma Prieta & 1989_October_18 & 6,9 & 288,6 & 9,3 \\
\hline 94 & $\mathrm{x}, \mathrm{y}$ & ST_47380 & Loma Prieta & 1989_October_18 & 6,9 & 271 & 29,66 \\
\hline 99 & $\mathrm{x}$ & ST_24087 & Northridge & 1994_January_17 & 6,7 & 298 & 11,02 \\
\hline 99 & $\mathrm{y}$ & ST_24303 & Northridge & 1994_January_17 & 6,7 & 316 & 23,62 \\
\hline 78 & $\mathrm{x}, \mathrm{y}$ & ERZ & Erzincan & 1992_March_13 & 6,6 & 274,5 & 8,97 \\
\hline 39 & $\mathrm{y}$ & AI_011_DZC & Duzce & 1999_November_12 & 7,1 & 282,2 & 5,27 \\
\hline
\end{tabular}

\subsection{Multi-layer feed-forward (MLF) neural networks}

MLF neural networks are the most used neural networks. They are applied to a wide variety of engineering related problems. A MLF neural network consists of neurons that are ordered into layers (Fig. 4). The first layer is called the input layer, the last layer is called the output layer in which the neurons are distributed in layers in such a way that two consecutive layers are fully connected; all the neurons of an input layer receive the outputs of all neurons in the previous layer. In feed-forward ANN, the neurons are organized in layers. There are no connections among neurons within the same layer; connections only exist between successive layers. Each neuron from layer 1 has connections to each neuron in layer $l+1$.

A signal propagates from the input layer to the output layer through several hidden layers. For each set of input signals, Feed-forward ANNs (Fig 4) allow information to travel one way only; from input to output. There is no feedback (loops) i.e. the output of any layer does not affect that same layer. A cell performs a weighted sum in which a transfer function is applied, and the output is transmitted to the following layer. 


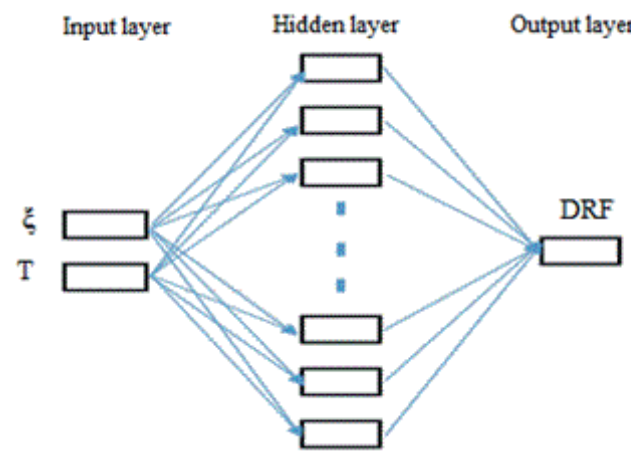

Fig. 4 Feed-forward multi-layer neural network.

The number of hidden layers, the number of cells per layer and their connections define the architecture of the neural network. The transfer function allowing to calculate the cell output is often a linear sigmoidal function [26].

The activation functions need to be differentiable and they are usually of the sigmoid shape. The most common activation function is

$$
f(\theta)=\frac{1}{1+e^{-\theta}}
$$

That is explained the general topology of a multilayer feed forward neural network. Neurons in each layer connect together by a weight coefficient. There is a transfer function which changes inputs to an output. Before using an artificial neural network, it is necessary to train network. Neural training is a method used to calculate the synaptic weights and bias in an iterative way until produces data compatible outputs. During training, network works with iterative method until it produces a new output. At the beginning of training process, initial weights are randomly given to connections. Inputs are inserted into input layer and then move forward through the hidden layer of neurons to the output layer. At the end, outputs would be compared with real outputs [25].

The choice of the architecture network is very important, as it affects both the model precision and the computing time. In order to determine the optimal architecture, we have considered various numbers of neurons in the hidden layer. For this purpose, we have considered the number of neurons in the hidden layer to be equal to 32 . The configuration of the ANN is 2-32-1; it expresses a neural network of 2 neurons in the input layer, 32 neurons in the hidden layer and 1 neuron in the output layer.

\subsection{Databases}

To build the database, the input parameters are the two structure characteristics in which the damping reduction factor depends, the damping ratio and the period value.

The output parameter corresponds to the damping reduction factor. These values of DRF are obtained through linear time-history analysis of SDOF with vibration period $T$ and damping ratio $\xi$.

A total of 285,000 response spectra and damping reduction factors was computed from the selected ground motions corresponding to 75 ground motions, 200 periods of vibration from 0.1 to $10 \mathrm{~s}, 19$ levels of damping ratio from 0.01 to 0.25 , for response spectrum of the displacement were computed for each period and each damping ratio.
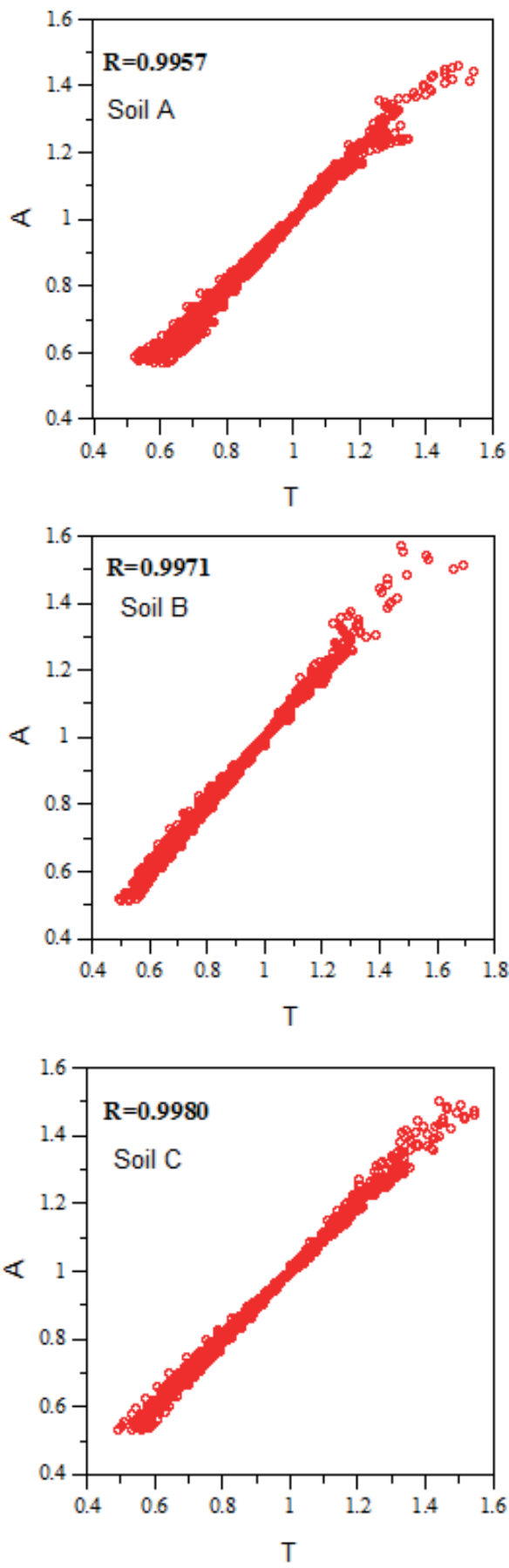

Fig. 5 Neural networks versus target DRF for different classes of sites

\subsection{Correlation analysis}

In order to verify the quality of the selected network (with 32 cells in the hidden layer), the entire set of data (i.e., data used for learning, validation and testing) has been passed through the network to perform a linear regression between the network outputs A and the corresponding targets $T$.

The correlation coefficient $\mathrm{R}$ allows us to measure the quality of the network prediction; a perfect prediction suggests that all the points are aligned along the diagonal $\mathrm{A}=T$ and the correlation coefficient is $\mathrm{R}=1$. Figure 5 represents the linear 
regression between the network outputs DRF and the corresponding targets DRF for all site classes. It is noticed from this figure that the fitting lines are practically superposed with the diagonal, and the correlation coefficient is very close to unity, which means that the neural network gives very accurate predictions of the damping reduction factor values.

\section{Results and discussions}

\subsection{Relative error}

The efficiency of the proposed method in this paper (ANN) is verified through the comparison with the exact mean values response spectra. In table 1 , we compare the obtained DRF for both methods for some pairs of values of damping and period. A relative error through the equation 3, was calculated between the DRF obtained from both ANN and EC 8 methods, and the DRF obtained from the exact mean values response spectra and these results are presented in the following table.

$$
\operatorname{ERR}_{\mathrm{ANN}}(\mathrm{T}, \xi)=\left|\frac{\mathrm{DRF}_{\text {real }}-\mathrm{DRF}_{\mathrm{ANN}}}{\mathrm{DRF}_{\text {real }}}\right| .
$$

We observed that the relative error committed while the use of the ANN is less than that resulted from the EC8 formulation. For instance, for $T=8 \mathrm{~s}$ and $\xi=20 \%$, we observed that the error for ANN equal to $0.2 \%$ and $34.0 \%$ for EC8 for soil A , $0.5 \%$ for ANN and $30.3 \%$ for EC8 for soil B and $0.2 \%$ for ANN and $21.2 \%$ for EC8 for soil C. It is clear from this results that the use of the ANN gives very good results comparing to EC8 formulation.

The mean of the errors obtained for $\xi=20 \%$ and for all periods used for this study can be reduced too. This error is equal to $1.25 \%$ for ANN and $20.11 \%$ for EC8 for soil A, $0.85 \%$ for ANN and $20.86 \%$ for EC8 for soil B, and $1.07 \%$ for ANN and 13.27 $\%$ for EC8 for soil C. It is evident that the proposed method closely follows the mean values of 'exact' dynamic analysis.

The ANN constitutes a sample and efficiency method to predict the DRF, and more exact than the models obtained from the nonlinear regression.

\subsection{Statistical results}

The accuracy of the presented methods is examined also by the use of two statistical terms, referring to a single group of earthquakes. The considered statistical indexes are the mean spectral ratio $\operatorname{MSR}(T, \xi)$ and the standard error $\operatorname{SE}(T, \xi)$ between approximate and exact high-damping displacement response spectra. They are defined by the following expressions:

$$
\begin{gathered}
\operatorname{MSR}(T, \xi)=\frac{1}{n} \sum_{i=1}^{n} \frac{D R F(T, \xi) * S d_{i}(T, \xi=5 \%)}{S d_{i}(T, \xi)} \\
S E(T, \xi)=\sqrt{\frac{1}{n-1} \sum_{i=1}^{n}\left(\frac{D R F(T, \xi) * S d_{i}(T, \xi=5 \%)-S d_{i}(T, \xi)}{S d_{i}(T, \xi)}\right)^{2}}
\end{gathered}
$$

Where $S d, i(T, \xi)$ is the real maximum displacement, obtained through linear time-history analysis of SDOF with vibration period $T$ and damping ratio $\xi$, due to the $i^{\text {th }}$ seismic ground motion, $\mathrm{DRF}=\operatorname{DRF}(T, \xi)$ is the damping reduction factor obtained through the method which we have to estimate its accuracy and $n$ is the total number of ground acceleration-time histories taken into account. For the evaluation of both MSR and $\mathrm{SE}$, a constant period increment of $0.05 \mathrm{sec}$ has been considered.

The standard error SE measures the scattering of the approximate maximum displacements around their exact values.

Values of SE close to zero imply a good accuracy of the approximate method in the prediction of the real maximum displacements.

In the figures below, Values of $\operatorname{MSR}(T, \xi)$ are smaller than 1.0 indicate that the approximate method underestimates, on average, the exact maximum elastic displacement, for that period and damping ratio. And values of $\operatorname{MSR}(T, \xi)$ larger than 1.0 mean that the approximate method generally overestimates the exact maximum elastic displacement, for that period and damping ratio.

Equations (4) and (5) are computed for linear elastic SDOF systems with viscous damping ratios $10 \%$, and with a set of 200 periods of vibration between 0.1 and $10 \mathrm{sec}$ with an incre-

\begin{tabular}{|c|c|c|c|c|c|c|c|}
\hline & $\mathrm{T}$ & $\xi$ & exact & EC8 & ANN & Error for EC8 (\%) & Error for ANN (\%) \\
\hline \multirow{4}{*}{ Soil A } & 0.5 & 0.07 & 0,892 & 0,913 & 0,900 & 2,31 & 0,82 \\
\hline & 2.0 & 0.10 & 0,839 & 0,817 & 0,846 & 2,71 & 0,85 \\
\hline & 4.5 & 0.14 & 0,827 & 0,726 & 0,843 & 12,25 & 1,97 \\
\hline & 8.0 & 0.20 & 0,956 & 0,633 & 0,956 & 33,87 & 0,01 \\
\hline \multirow{4}{*}{ Soil B } & 0.5 & 0.07 & 0,888 & 0,913 & 0,914 & 2,81 & 2,99 \\
\hline & 2.0 & 0.10 & 0,854 & 0,817 & 0,853 & 4,44 & 0,12 \\
\hline & 4.5 & 0.14 & 0,856 & 0,726 & 0,854 & 15,27 & 0,22 \\
\hline & 8.0 & 0.20 & 0,903 & 0,633 & 0,906 & 29,97 & 0,26 \\
\hline \multirow{4}{*}{ Soil C } & 0.5 & 0.07 & 0,889 & 0,913 & 0,899 & 2,71 & 1,14 \\
\hline & 2.0 & 0.10 & 0,817 & 0,817 & 0,827 & 0,09 & 1,18 \\
\hline & 4.5 & 0.14 & 0,811 & 0,726 & 0,798 & 10,55 & 1,65 \\
\hline & 8.0 & 0.20 & 0,801 & 0,633 & 0,797 & 21,04 & 0,52 \\
\hline
\end{tabular}
ment of $0.05 \mathrm{sec}$.

Table 4 Damping reduction factors for EC 8 and ANN 

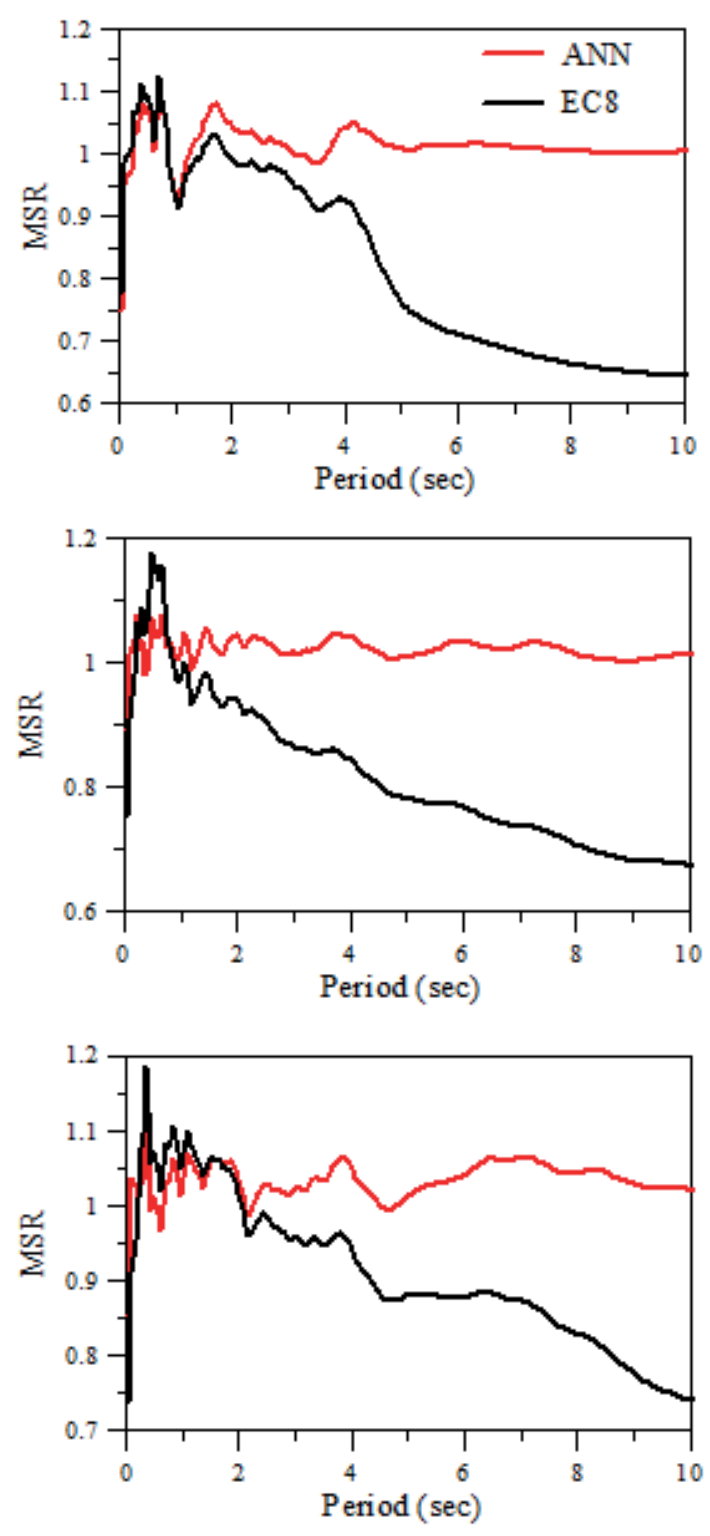

Fig. 6 mean spectral ratios for different classes of EC8

Figures 6 and 7 show the statistical terms derived from the obtained records for different soils. The following observations can be obtained:

1. The mean spectral ratio obtained by ANN has a little perturbation around the value 1 . That is means that the ANN gives approximately the same values of the damping reduction actor as the values obtained through the linear time-history analysis (exact values). The results of EC8 formulation underestimate the DRF; it gives very different values than the exact values especially for $T>2 \mathrm{sec}$. It is clear from these results that the use of the ANN gives more exact values than EC8.

2. The graphs of The standard error SE presented at the figure 7 shows that the error committed while the use of the ANN for the computing of the DRF is less than the error committed while the use of the EC8. The graphs of the SE for the ANN are more close to zero than the graphs of EC8, especially for Soil A and B when the error for EC8 have a value greater than 0.35 while that of the ANN is less than 0.1 for $T>4$ sec.
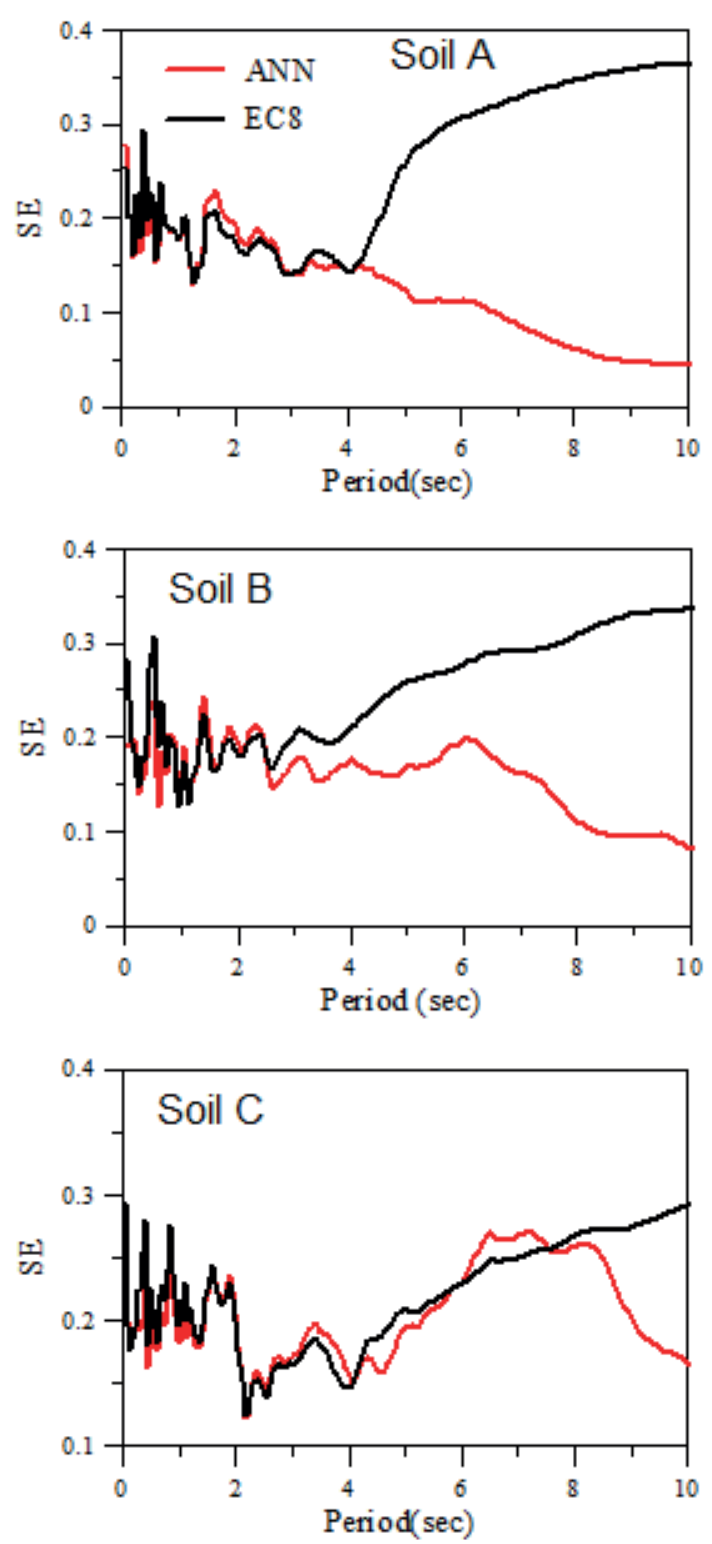

Fig. 7 Standard error of DRF for different classes of EC8

\subsection{Comparison with literature formulation}

In this section, a comparison between different approximate formulations of DRF from the literature and the DRF values obtained in this study through the ANN is presented, for different values of $\xi(7,10,20$ and $25 \%$, respectively).

The approximate formulations of the DRF considered herein are those proposed by: (i) Bommer et al (2000) (EC8), (ii) Lin and Chang (2003), (iii) Hatzigeorgiou (2010) and (iv) Zhou et al (2003) [27].

The DRF proposed by Bommer et al. (2000) is expressed by the following formula:

$$
D R F=\sqrt{\frac{10}{5+\xi}} \geq 0.55
$$

It has been adopted in the European seismic code (EC8 EN 2004).

Hatzigeorgiou (2010) has proposed a new method for evaluating DRF taking into account the influence of soil conditions and ground motion type (use of natural or artificial 
accelerograms, near- or far-fault earthquakes), besides viscous damping ratio and period of vibration:

$$
\begin{aligned}
& \operatorname{DRF}(\xi, T)=1+(\xi-5) \cdot\left[1+c_{1} \cdot \ln (\xi)+c_{2} \cdot(\ln (\xi))^{2}\right] \\
& \cdot\left[c_{3}+c_{4} \cdot \ln (T)+c_{5} \cdot(\ln (T))^{2}\right\rceil
\end{aligned}
$$

The values of the coefficients ci are given in (Hatzigeorgiou 2010) as a function of the soil type and the type of seismic ground motions.

Lin and Chang (2003) proposed the following period dependent formulation of DRF:

$$
D R F=1-\frac{a T^{0.30}}{(T+1)^{0.65}}
$$

where $a=1.303+0.436 \ln (\xi)$.

The expression proposed by Zhou et al (2003) was adopted in the Chinese code for seismic design of buildings:

$$
D R F=1+\frac{0.05-\xi}{0.06+1.4 \times \xi}
$$

The comparison between the exact DRF values and the different approximate formulations of DRF and the values obtained through the ANN for four values of damping (7, 10, 20 and $25 \%$ ) is presented in fig. 8 . This comparison is presented only for the soil A because that all the seismic code (included the EC8) present the same formulation for all the soils type.
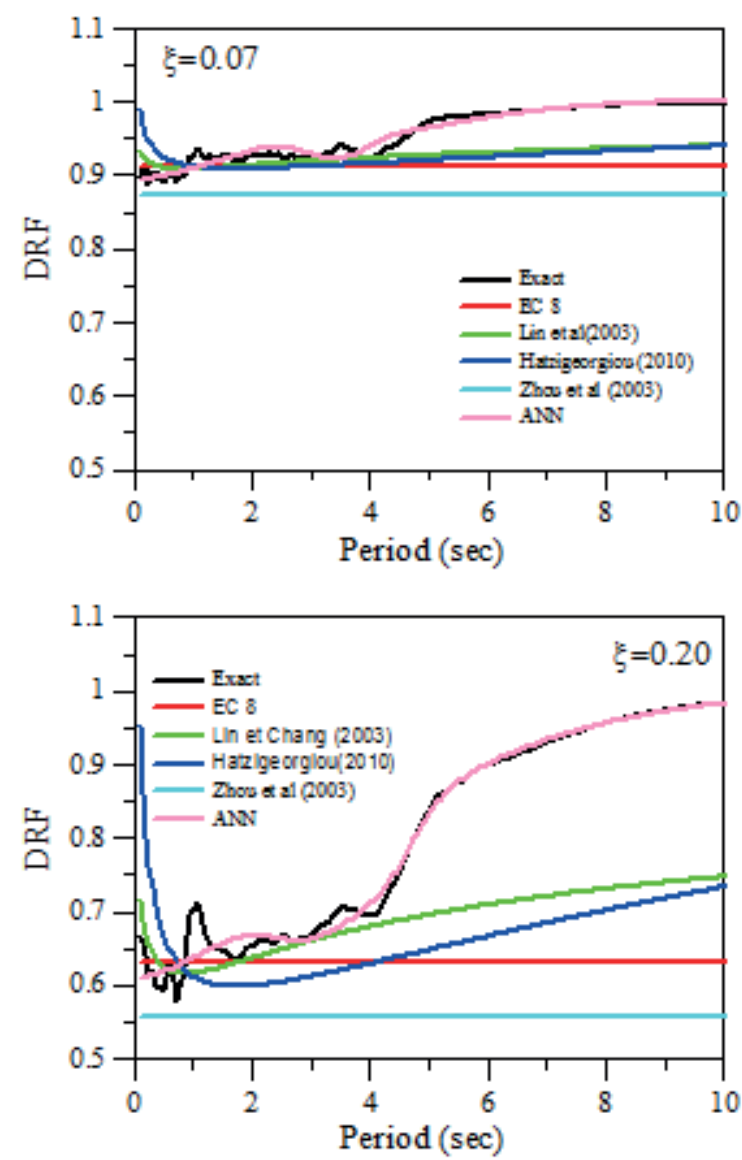

From the previous figures the following conclusions can be drawn:

1. The differences between the approximated DRF formulations and the exact results increase while increasing the damping ratio. This difference is increased for $T>4 \mathrm{sec}$, and presents a maximal value for $T=10 \mathrm{sec}$.

2. According to the figure, for $T<0.7 \mathrm{sec}$, the most important values of the DRF, ie, more conservative, are those obtained from the formulation of Hatzigeorgiou. Although, the lowest (more Nonconservative) are those provided by Zhou et al. the formula of the EC 8 overestimate the structures seismic response in this range of periods. This overestimation puts to the structures built using the values of response in the safety zone.

3. For $0.7<T<4 \mathrm{sec}$, the DRF values of the EC 8 are smaller than the exact results, it means that the EC8 formulation underestimates the seismic response for the structures in this range of periods. This presents a seismic risk for this structures. The formula of Lin et al constitutes a good estimator of DRF values in the range. The ANN constitutes the closest model to the exact results.

4. For $T>4 \mathrm{sec}$, all formulations give DRF values very smaller than the exact results. For instance, for $T=10$, the DRF obtained through the EC8 formulation is $=0.577$ and the exact values is 0,975 while the ANN gives value DRF $=0.976$. This difference, between the exact and the EC8
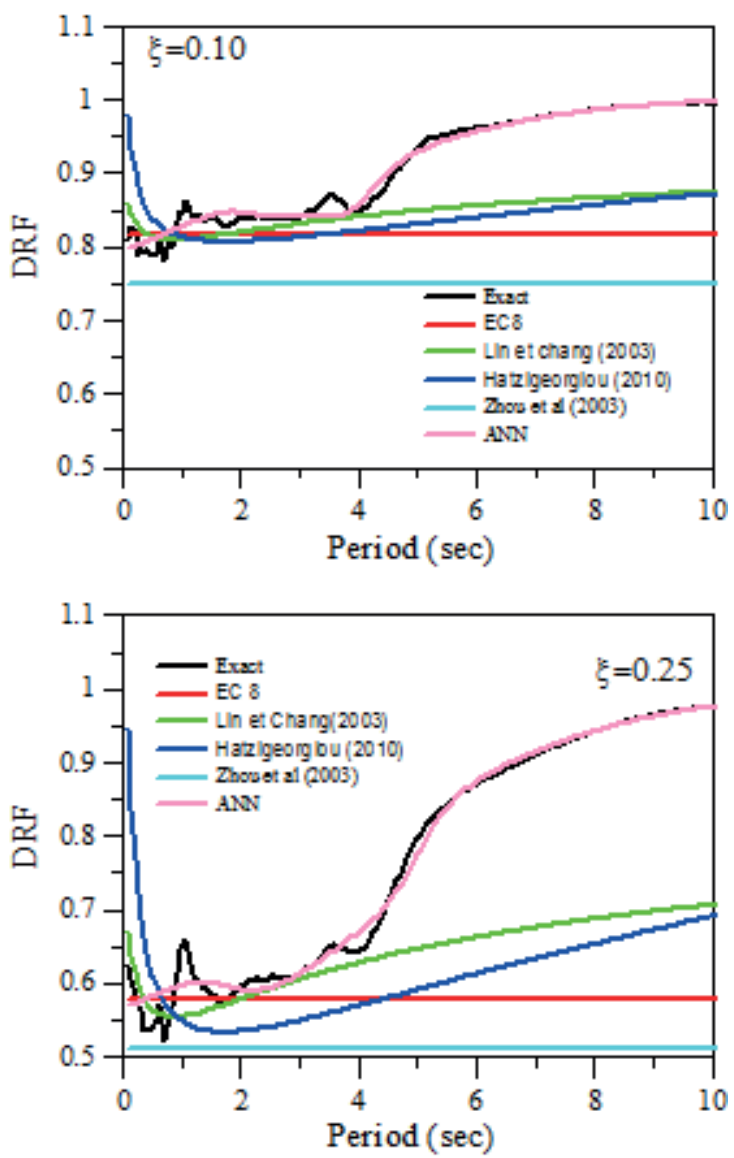

Fig. 8 Comparison between different approximate formulations of DRF and the exact values of DRF 
formulation, up to $40 \%$ means that the error for the seismic response can exceed the $40 \%$. This implies the importance of the problem and the damage that this error can introduced to the structure dimensioned considering a worn value of DRF (i.e a wrong value of design seism response.

5. The results obtained through the ANN method are very close to the exact results, the tow curves are practically superposed for all the periods. This provides the good approximation of the ANN and the accuracy of this method for the estimation of the DRF values.

\section{Conclusions}

The accuracy of the ANN for the evaluation of damping reduction factor for high damping response spectra for EC8 has been examined. The efficiency of the developed ANN procedure was examined in light of three parameters characterizing the regression analysis: the correlation coefficient $\mathrm{R}$, the mean spectral ratio $\operatorname{MSR}(T, \xi)$ and the standard error SE $(T, \xi)$. The obtained results corroborate for a good matching of the estimated DRF values with the exact results.

The conclusions and suggestions drawn from this study can be summarized as follows.

The relative error committed while the use of the ANN is less than that resulted from the EC8 formulation. For instance, for $\mathrm{T}=8 \mathrm{~s}$ and $\xi=20 \%$, we observed that the error for ANN equal to $0.2 \%$ and $34.0 \%$ for EC8 for soil A, $0.5 \%$ for ANN and $30.3 \%$ for EC8 for soil B and $0.2 \%$ for ANN and $21.2 \%$ for EC8 for soil C. It is clear from these results that the use of the ANN gives very good results comparing to EC8 formulation.

According to the results, the DRF values of the EC8 are smaller than the exact results, it means that the EC8 formulation underestimates the seismic response for the structures in range of periods $T>0.7$. This presents a seismic risk for these structures. For instance, for $T=10$, the DRF obtained using the formulation of EC8 is 0.577 and the exact values is 0,975 while the ANN gives value DRF $=0.976$. This difference, between the exact and the EC8 formulation, up to $40 \%$ means that the error for the seismic response can exceed the $40 \%$. This implies the importance of the problem and the damage that this error can introduce to the structure designed considering a worn value of DRF (i.e wrong value of design seismic response.

The ANN constitutes a sample and efficiency method to predict the DRF, and more exact than all formulations in literature.

The ANN can be limited when the number of inputs values is limited, it means that we can have a poor regression. The only condition to obtain good results using the ANN is to find enough records that can be representative of the selected code.

The ANN is a new and accurate method for estimating DRF values, the proposed approach is original and the associated results are interesting and promising. The developed ANN can be used to estimate the DRF for different seismic codes with a very good approximation.

\section{References}

[1] Cameron, W. I., Green, R. A. "Damping Correction Factors for Horizontal Ground-Motion Response Spectra". Bulletin of the Seismological Society of America, 97(3), pp. 934-960, 2007. https://doi. org/10.1785/0120060034

[2] Stafford, P. J., Mendis, R., Bommer, J. J. "Dependence of Damping Correction Factors for Response Spectra on Duration and Numbers of Cycles". Journal of Structural Engineering, 134(8), pp. 1364-1373. 2008. https://doi.org/10.1061/(ASCE)0733-9445(2008)134:8(1364)

[3] Tolis, S. V., Faccioli, E. "Displacement design spectra". Journal of Earthquake Engineering, 3(1), pp. 107-126, 1999. https://doi. org/10.1080/13632469909350342

[4] EN 1998-1 (English): Eurocode 8: Design of structures for earthquake resistance - Part 1: General rules, seismic actions and rules for buildings [Authority: The European Union Per Regulation 305/2011, Directive 98/34/EC, Directive 2004/18/EC]. 2004.

[5] Lin, Y. Y., Miranda, E., C. Chang, K. C. "Evaluation of damping reduction factors for estimating elastic response of structures with high damping". Earthquake Engineering Structural Dynamics, 34(11), pp. 1427-1443, 2005. https://doi.org/10.1002/eqe.499

[6] Lin, Y. Y., Chang, K. C. "Study on Damping Reduction Factor for Buildings under Earthquake Ground Motions". Journal of Structural Engineering, 129(2), pp. 206-214, 2003. https://doi.org/10.1061/ (ASCE)0733-9445(2003)129:2(206)

[7] Lin, Y. Y., Chang, K. C. "Effects of Site Classes on Damping Reduction Factors". Journal of Structural Engineering, 130(11), pp. 1667-1675, 2004. https://doi.org/10.1061/(ASCE)0733-9445(2004)130:11(1667)

[8] Cardone, D., Dolce, M., Rivelli, M. "Evaluation of reduction factors for high-damping design response spectra". Bulletin of Earthquake Engineering, 7(1), pp. 273-291, 2009. https://doi.org/10.1007/s10518-008-9097-y

[9] NEHRP, Recommendedprovisions for seismic regulations for new buildings.Washington (DC): Federal Emergency ManagementAgency, 2000, 2003.

[10] Hao, A., Zhou, D., Li, Y. and Zhang, H. "Effects of moment magnitude, site conditions and closest distance on damping modification factors". Soil Dynamics and Earthquake Engineering, 31(9), pp. 1232-1247, 2011. https://doi.org/10.1016/j.soildyn.2011.05.002

[11] Athanassiadou, C. J., Karakostas, C. Z., Margaris, B. N., Kappos, A. J. "Displacement spectra and displacement modification factors, based on records from Greece". Soil Dynamics and Earthquake Engineering, 31(12), pp. 1640-1653, 2011. https://doi.org/10.1016/j.soildyn. 2011.06.008

[12] Hatzigeorgiou, G. D. "Damping modification factors for SDOF systems subjected to near-fault, far-fault and artificial earthquakes". Earthquake Engineering \& Structural Dynamics, 39(11), pp. 1239-1258, 2010. https://doi.org/10.1002/eqe.991

[13] Lin, Y. Y. "Statistical study on damping modification factors adopted in Taiwan's seismic isolation design code by using the 21 September 1999 Chi-Chi earthquake, Taiwan". Engineering Structures, 29(5), pp. 682-693, 2007. https://doi.org/10.1016/j.engstruct.2006.06.006

[14] Priestley, M. J. N. "Myths and Fallacies in Earthquake Engineering". Revisited. IUSS Press: Italy, 2003.

[15] Ashour, S. A. "Elastic seismic response of buildingswith supplemental damping". Ph.D. dissertation. Department of Civil Engineering, University ofMichigan, January 1987.

[16] Caltrans "California Department of Transportation. Seismic Design Criteria Version 1.2.". Sacramento. 2001

[17] Wu, J., Hanson, R. D. "Study of Inelastic Spectra with High Damping". Journal of Structural Engineering, 115(6), pp. 1412-1431, 1989. https:// doi.org/10.1061/(ASCE)0733-9445(1989)115:6(1412) 
[18] Naeim, F., Kircher, C. A. "On the damping adjustment factors for earthquake response spectra". The Structural Design of Tall and Specal Buildings, 10(5), pp. 361-369, 2001.b https://doi.org/10.1002/tal.180

[19] Ramirez, O. M., Constantinou, M. C., Kircher, C. A., Whittaker, A. S., Johnson, M. W., Gomez, J. D., Chrysostomou, C. A. "Development and evaluation of simplified procedures for analysis and design of buildings with passive energy dissipation systems". MCEER-00-0010. New York: Multidisciplinary Center for Earthquake Engineering Research (MCEER), University of New York at Buffalo; 2000.

[20] Ramirez, O. M., Constantinou, M. C., Whittaker, A. S., Kircher, C. A., Chrysostomou, C. Z. "Elastic and inelastic seismic response of buildings with damping systems". Earthquake Spectra, 18(3), pp. 531-547, 2002. https://doi.org/10.1193/1.1509762

[21] Malhotra, P. K. "Smooth spectra of horizontaland vertical ground motions". Bulletin of the Seismological Society of America, 96, 506-518, 2006. https://doi.org/10.1785/0120050062

[22] Newmark, N. M., Hall, W. "Earthquake Spectra and Design". EERI Monographs. p. 103, 1982.
[23] Bommer, J. J., Mendis, R. "Scaling of spectral displacement ordinates with damping ratios". Earthquake Engineering \& Structural Dynamics, 34(2), pp. 145-165, 2005. https://doi.org/10.1002/eqe.414

[24] Iervolino, I., Galasso, C., Cosenza, E. "REXEL : computer aided record selection for code-based seismic structural analysis". Bulletin of Earthquake Engineering, 8(2), pp. 339-362, 2010. https://doi.org/10.1007/ s10518-009-9146-1

[25] Tardast, A., Rahimnejad, M., Najafpour, G., Pirzade, K., Mokhtarian, N. "Prediction of bioelectricity production by neural network". Journal of Biotechnology and Pharmaceutical Research, 3(3), pp. 62-68, 2012.

[26] Badaoui, M., Chateauneuf, A., Fournely, E., Bourahla, N., Bensaïbi, M. "Evaluation of accidental eccentricity for buildings by artificial neural networks". Structural engineering \& mechanics, 41(4), pp. 527-538, 2012.

[27] Zhou, F., Wenguang, L., Xu, Z. "State of the arton applications, R\&D and design rules for seismicisolation in China". In: Proc. 8th world seminar onseismic isolation, energy dissipation and activevibration control of structures, Yerevan, Armenia, 2003. 